CLINICAL STUDY

\title{
The impact of the CAG repeat polymorphism of the androgen receptor gene on muscle and adipose tissues in 20-29-year-old Danish men: Odense Androgen Study
}

\author{
Torben Leo Nielsen ${ }^{1}$, Claus Hagen ${ }^{1}$, Kristian Wraae ${ }^{1}$, Lise Bathum ${ }^{2}$, Rasmus Larsen ${ }^{3}$, Kim Brixen ${ }^{1}$ \\ and Marianne Andersen ${ }^{1}$ \\ Departments of ${ }^{1}$ Endocrinology and ${ }^{2}$ Biochemistry, Pharmacology, and Genetics, Odense University Hospital, Sdr. Boulevard, 5000 Odense C, Denmark \\ and ${ }^{3}$ Institute of Mathematical Modelling, Technical University of Denmark, Copenhagen, Denmark
}

(Correspondence should be addressed to T L Nielsen; Email: torben@dsa-net.dk)

\begin{abstract}
Background: The number of CAG repeats $\left(\mathrm{CAG}_{n}\right)$ within the CAG repeat polymorphism of the androgen receptor gene correlates inversely with the transactivation of the receptor.

Objective: To examine the impact of $\mathrm{CAG}_{n}$ on muscle, fat distribution, and circulating androgen levels. Design, settings and participants: Population-based, cross-sectional study of 783 Danish men aged 20-29 years.

Methods: Genotyping was performed in 767 men. Areas of thigh and lower trunk muscle (muscle thigh $_{\text {. }}$ and muscle lower trunk $_{\text {low }}$, subcutaneous adipose tissues $\left(\mathrm{SAT}_{\text {thigh }}\right.$ and $\mathrm{SAT}_{\text {lower trunk }}$ ), and deep adipose tissues (i.m. and visceral) were measured in 393 men by magnetic resonance imaging (MRI). Lean body mass (LBM) and fat mass (FM) were measured in all men by whole body dual-energy X-ray absorptiometry (DEXA). The absolute areas acquired by MRI were the main outcomes. The absolute DEXA measurements and relative assessments of both modalities were considered as the secondary outcomes.

Results: $\mathrm{CAG}_{n}$ (range: 10-32) correlated inversely with absolute muscle thigh $(r=-0.108)$, absolute muscle lower trunk $(r=-0.132)$, relative muscle thigh $(r=-0.128)$, relative muscle lower trunk $_{\text {ank }}$ $(r=-0.126)$, relative $\mathrm{LBM}_{\text {lower extremity }}(r=-0.108)$, and relative $\operatorname{LBM}_{\text {total }}(r=-0.082)$, and positively with relative $\mathrm{SAT}_{\text {thigh }}(r=0.137)$, relative $\mathrm{SAT}_{\text {lower trunk }}(r=0.188)$, relative $\mathrm{FM}_{\text {lower extremity }}(r=0.107)$, and relative $\mathrm{FM}_{\text {total }}(r=0.082)$. These relationships remained significant, controlling for physical activity, smoking, chronic disease, and age. $\mathrm{CAG}_{n}$ did not correlate with any circulating androgen.

Conclusions: The CAG repeat polymorphism affects body composition in young men: absolute

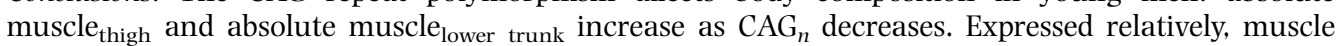
areas and LBM increase, while SAT and FM decrease as $\mathrm{CAG}_{n}$ decreases. The polymorphism does not affect deep adipose tissues or circulating androgen levels in young men.
\end{abstract}

European Journal of Endocrinology 162 795-804

\section{Introduction}

Androgens mediate their effects on target organs via the androgen receptor, which is expressed in many tissues including muscular and adipose tissues (1). The transcriptional activity of the hormone-receptor complex is inversely correlated with the number of CAG repeats $\left(\mathrm{CAG}_{n}\right)$ in a sequence of the androgen receptor gene (the CAG repeat polymorphism) $(2,3)$. Fat mass (FM), insulin, and leptin increase with increasing $\mathrm{CAG}_{n}$ (4). Currently, it is unknown whether the association with FM is ubiquitously present or restricted to subcutaneous adipose tissue (SAT) or visceral adipose tissue (VAT). Moreover, positive relations between $\mathrm{CAG}_{n}$ and fat-free mass were reported in two cohorts of 294 and 112 males of a broad range of ages (5). Androgen levels are not related to $\mathrm{CAG}_{n}$ in younger men, but decline more rapidly with age in men with lower repeat numbers $(5,6)$. This has been explained by diminished central androgen receptor activity in older men with longer alleles resulting in a decreased negative feedback on the hypothalamic-pituitarygonadal (HPG) axis, leading to relatively higher androgen levels $(5,6)$.

We included a population-based cohort of 783 young men aged 20-29 years to address the primary hypothesis that in young men, $\mathrm{CAG}_{n}$ is inversely correlated with muscle area/mass, and is positively correlated with SAT and VAT. Finally, we examined the circulating levels of androgens in relation to $\mathrm{CAG}_{n}$. 


\section{Methods}

\section{Subjects}

Odense Androgen Study is a population-based cohort study of 783 Danish men aged 20-29 years. Informed consent was obtained from all subjects. The study population is described in detail elsewhere $(7,8)$. In brief, 3000 men were randomly drawn from the Danish Central Personal Registry, and they received a questionnaire. Respondents $(n=2042)$ were invited and 784 men were included, of which one dropped out. The 783 men matched the county population as regards body mass index, chronic disease, medication, physical activity, tobacco exposure, sociodemography, and socioeconomic status (7). Three anabolic steroid users were excluded from the analysis. Genotyping of the CAG repeat polymorphism was performed in 767 men, magnetic resonance imaging (MRI) in 406 men (genotyped: $n=393$ ), and dual-energy X-ray absorptiometry (DEXA) in all men. The examinations took place from March 2002 to May 2003. The local ethical review board gave approval for the study (\#20010198), which was conducted according to the Declaration of Helsinki.

\section{Physical examination and medical history}

A physical examination was performed retrieving the following data by questionnaire, by interview, and from electronic hospital records: chronic disease (yes/no); medication (yes/no); smoking (cigarettes/day); anabolic steroid abuse (yes/no); and physical activity in terms of jogging ( $\mathrm{km} /$ week), cycling $(\mathrm{km} /$ week), strength training (yes/no), and other sports (h/week).

\section{Biochemistry}

Subjects arrived fasting at $0730-0930 \mathrm{~h}$ for venous blood sampling. Total testosterone (TT), androstenedione, dihydrotestosterone (DHT), and estradiol $\left(\mathrm{E}_{2}\right)$ were measured by an in-house assay $(9,10)$ using extraction, celite chromatography, and a final RIA (intra-assay coefficient of variation $(\mathrm{CV})$ values: 8.2 , 9.4, 9.1, and $7.4 \%$ and inter-assay $\mathrm{CV}$ values: 13.8 , $11.4,11.0$, and $10.5 \%$ respectively). The accuracy of the TT assay was monitored in an external quality assessment program (German Society of Clinical Chemistry): the mean bias in 20 consecutive control samples was $+5.4 \%$ (95\% confidence interval (CI): 1.2-9.7\%). Bioavailable testosterone was calculated from a validated formula (11) using TT, SHBG (Immulite 2000, Diagnostic Products Corporation, Los Angeles, CA, USA; intra-assay and inter-assay CV values: 3.0 and $5.0 \%$ respectively), and albumin (Roche/Hitachi 917, Roche Diagnostics; intra-assay and inter-assay $\mathrm{CV}$ values: 0.7 and $2.0 \%$ respectively).

\section{Genotyping}

DNA was isolated from whole blood using QIAamp DNA Blood Midi Kits (Qiagen). $\mathrm{CAG}_{n}$ was determined in 767 men. The genotyping was performed with the primers GAGsense: TCCGAATCTGTTCCGAGCGTGC and CAGanti: GCTGTGAAGGTTGCTGTTCCTCAT. For detection, the sense primer was labeled with 6-FAM. DNA amplification was performed in a total volume of $6 \mu \mathrm{l}$ containing $1 \times$ PCR buffer, $1.5 \mathrm{mM}$ $\mathrm{MgCl}_{2}, 200 \mu \mathrm{M}$ of each dNTP (Roche), $167 \mathrm{nM}$ of each primer (DNA Technology, Aarhus, Denmark), 0.1 U Taq DNA polymerase (Sigma), and $~ 10$ ng template DNA. The annealing temperature of the PCR was $66^{\circ} \mathrm{C}$. PCR products were resolved on the MegaBACE 1000 according to the manufacturer's instructions, and were analyzed using the Fragment Profiler software (Amersham Biosciences). Approximately 10\% of the samples were sequenced with the primer CAGseq: GAATCTGTTCCAGAGCGTGCG as a quality control.

\section{Body composition}

MRI was performed in the first 406 consecutively included subjects with an open, low field (0.2 Tesla) MR unit (Magnetom Open Viva, Siemens, Erlangen, Germany). Muscle thigh, $\mathrm{SAT}_{\text {thigh}}$, and intramuscular adipose tissue (IMAT) $)_{\text {thigh }}$ were determined in one femoral slice (equidistant from the trochanter major and patella) using a T1-weighted gradient-echo sequence (repetition time: $370 \mathrm{~ms}$, echo time: $15 \mathrm{~ms}$, acquisition matrix: $512 \times 512$, field of view: $230 \mathrm{~mm}$ ). The intraobserver $C V$ values of muscle ${ }_{\text {thigh }}$ and $\mathrm{SAT}_{\text {thigh }}$ were 1.1 and $3.0 \%$ respectively. Three slices of the lower trunk $(10 \mathrm{~mm}$ thick, $20 \mathrm{~mm}$ apart, lower slice at the dorsal, intervertebral space of L4/L5) were recorded using an axial, T1-weighted gradient-echo sequence (repetition time: $450 \mathrm{~ms}$, echo time: $15 \mathrm{~ms}$, acquisition matrix: $512 \times 288$, field of view: $400 \mathrm{~mm}$ ). A bias correction algorithm was developed to ensure uniform pixel intensities of adipose tissue throughout all images (12). The area of total lower trunk adipose tissue was assessed from bimodal histograms discriminating between adipose and non-adipose tissues (Adobe Photoshop 7.0; Adobe Systems, Inc.). The intra-abdominal compartment was demarcated, and VAT was quantified. $\mathrm{SAT}_{\text {lower trunk }}$ was computed by subtracting peri-vertebral and bone marrow adipose tissues and VAT from the area of total abdominal adipose tissue. Muscle lower trunk was computed by subtracting the area of the peritoneal cavity, retroperitoneal non-muscular tissues, $\mathrm{SAT}_{\text {lower trunk, }}$ peri-vertebral adipose tissues, and calcified tissue from the total lower trunk area. The reported areas of muscle $_{\text {lower trunk }}, \mathrm{SAT}_{\text {lower trunk, }}$ and VAT represent the mean of the three slices. The intraobserver $\mathrm{CV}$ values of muscle $_{\text {lower trunk }}, \mathrm{SAT}_{\text {lower trunk, }}$, and VAT were $4.7,1.7$, and $7.2 \%$ respectively. Lean body mass $\left(\mathrm{LBM}_{\text {total }}\right)$, 
$\mathrm{LBM}_{\text {upper extremity, }} \mathrm{LBM}_{\text {lower extremity, }}$ and $\mathrm{LBM}_{\text {central }}$ were measured by DEXA using a Hologic 4500A densitometer (Waltham, MA, USA). Body weight (Seca, Roskilde, Denmark) and height measured by a stadiometer were recorded.

\section{Data analysis}

The MRI and DEXA measurements were expressed as absolute and relative outcomes. The relative outcomes were generated in order to evaluate the amount of a specific tissue in proportion to the total area (MRI) or in proportion to the total mass (DEXA) of the region of interest. Regarding the expression of the relative outcomes, the method of adjustment using linear regression is more correct than the use of ratios or percentages $(13,14)$, because the relationships between specific tissue and total area/mass - despite being linearhad non-zero intercepts in all cases; thus, linear regression was used to compute relative muscle thigh $_{\text {tion }}$

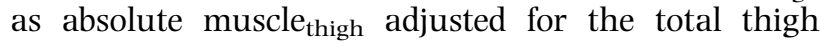
area. Similarly, relative muscle lower trunk $_{\text {was }}$ expressed as absolute muscle $e_{\text {lower trunk }}$ adjusted for the total lower trunk area. Both $\mathrm{SAT}_{\text {thigh }}$ and $\mathrm{IMAT}_{\text {thigh }}$ were adjusted for total thigh area, SAT $_{\text {lower trunk }}$ and VAT for total lower trunk area, $\mathrm{LBM}_{\text {total }}$ and $\mathrm{FM}_{\text {total }}$ for total body mass, $\mathrm{LBM}_{\text {lower extremity }}$ and $\mathrm{FM}_{\text {lower extremity }}$ for total lower extremity mass, $\mathrm{LBM}_{\text {upper extremity }}$ and $\mathrm{FM}_{\text {upper extremity }}$ for total upper extremity mass, and both $\mathrm{LBM}_{\text {central }}$ and $\mathrm{FM}_{\text {central }}$ were adjusted for total central mass.

To overcome the issue of multiple testing, the six absolute MRI measurements (muscle thigh $_{\text {, }}$ muscle $_{\text {lower trunk, }} \mathrm{SAT}_{\text {thigh }}, \mathrm{IMAT}_{\text {thigh}}, \mathrm{SAT}_{\text {lower trunk, }}$, and VAT) were considered as the main outcome measures of the study, whereas the eight absolute DEXA measurements $\left(\mathrm{LBM}_{\text {total }}, \mathrm{LBM}_{\text {lower }}\right.$ extremity, $\mathrm{LBM}_{\text {upper extremity, }} \mathrm{LBM}_{\text {central }}, \mathrm{FM}_{\text {total }}, \mathrm{FM}_{\text {lower extremity }}$

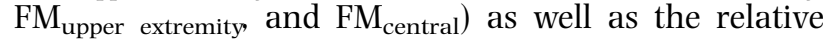
outcomes of all 14 MRI and DEXA measurements were given less emphasis as suggested by Altman (15).

The correlation strength between $\mathrm{CAG}_{n}$ and the outcomes were examined using Pearson's correlation analysis. Analyses were performed i) with all men included and ii) excluding men with low TT, defined as $\mathrm{TT}<12.5 \mathrm{nmol} / \mathrm{l}$ in the present population $(7,8)$. Any significant effect of genotype on an outcome was further analyzed using linear regression analysis to express the effect (slope) as the change in muscle area or LBM per repeat. Finally, multiple regression analyses were performed to examine the effect after adjustment for physical activity, smoking, chronic disease, and age. TT, DHT, and $\mathrm{E}_{2}$ were also adjusted for in those analyses that examined muscle area or LBM. All regression analyses were performed using robust s.E.M.'s, and $\mathrm{CAG}_{n}$ was treated as a continuous variable.

$\mathrm{CAG}_{n}$ was nearly normally distributed, but it did not become perfectly Gaussian upon logarithmic, root, power, or reciprocal transformation. Muscle thigh and $\mathrm{LBM}_{\text {lower }}$ extremity were normally distributed. Natural logarithm transformations provided Gaussian distributions of the remaining outcomes and all circulating androgens. Means reported are geometric, unless otherwise stated. The level of significance was set at $P<0.05$. Data were analyzed using Stata Statistical/Data Analysis software version 8.2 (StataCorp, College Station, TX, USA).

\section{Results}

$\mathrm{CAG}_{n}$ was distributed around a median of 21 repeats with a minimum and a maximum of 10 and 32 repeats respectively (Fig. 1). The subject characteristics are given in Table 1.

\section{Main outcomes - absolute MRI outcomes}

$\mathrm{CAG}_{n}$ was inversely correlated with absolute muscle thigh $_{\text {th }}$

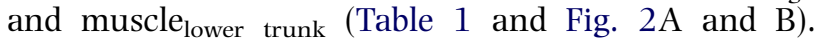
$A$ reduction of ten $C A G$ repeats equaled an increase in

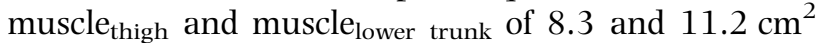
respectively. Among the remaining four absolute MRI outcomes, neither $\left(\mathrm{SAT}_{\text {thigh }}\right.$ and $\left.\mathrm{SAT}_{\text {lower trunk }}\right)$ nor deep adipose tissues (IMAT thigh and VAT) correlated significantly with $\mathrm{CAG}_{n}$ (Table 1).

\section{Secondary outcomes}

Regarding the relative outcomes, inverse correlations with $\mathrm{CAG}_{n}$ were found for relative muscle thigh $_{\text {, relative }}$

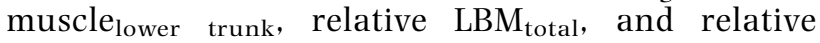
$\mathrm{LBM}_{\text {lower extremity }}$ (Fig. 3A-D). A reduction of ten CAG repeats was equivalent with increments in relative

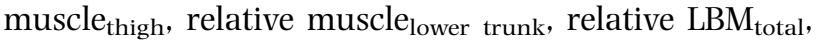

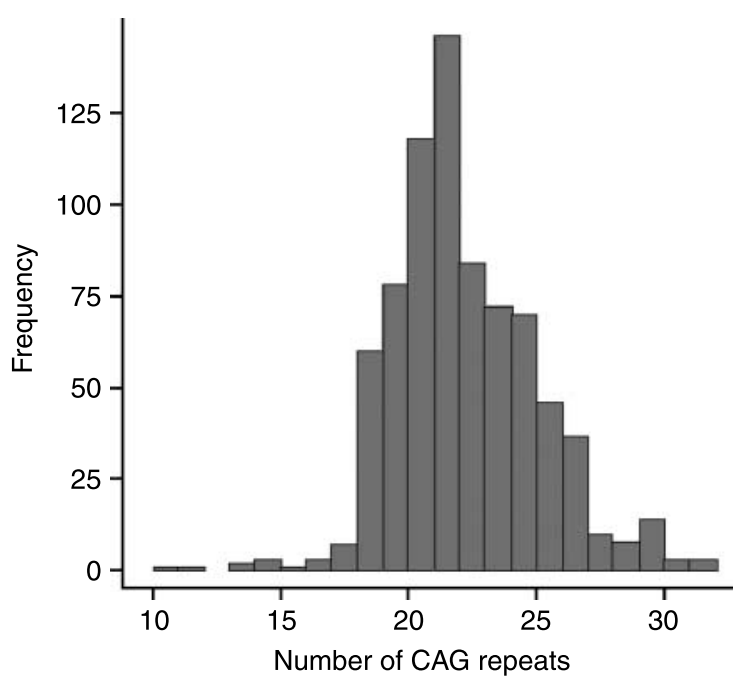

Figure 1 The frequency distribution of the number of CAG repeats in 767 men aged 20-29 years, in whom the CAG repeat polymorphism of the androgen receptor gene was genotyped in the Odense Androgen Study. 
Table 1 Subject characteristics of the 767 men aged 20-29 years, in whom the CAG repeat polymorphism of the androgen receptor gene was genotyped.

\begin{tabular}{|c|c|c|c|c|}
\hline & $n$ & $\begin{array}{l}\text { Geometric } \\
\text { mean }\end{array}$ & $\begin{array}{l}2.5 \text { and } 97.5 \\
\text { percentiles }\end{array}$ & $\begin{array}{l}\text { Correlation }^{\mathrm{a}} \text { with } \\
\text { CAG repeats }\end{array}$ \\
\hline \multicolumn{5}{|l|}{ Body composition } \\
\hline Thigh muscle area $\left(\mathrm{cm}^{2}\right)$ & 393 & 164 & 124-207 & $-0.108^{\star}$ \\
\hline Lower trunk muscle area $\left(\mathrm{cm}^{2}\right)$ & 393 & 189 & $149-238$ & $-0.132^{\dagger}$ \\
\hline Thigh subcutaneous adipose tissue $\left(\mathrm{cm}^{2}\right)$ & 393 & 50.6 & $19.1-118$ & 0.046 \\
\hline Thigh i.m. adipose tissue $\left(\mathrm{cm}^{2}\right)$ & 393 & 4.3 & $1.5-12.8$ & -0.019 \\
\hline Lower trunk subcutaneous adipose tissue $\left(\mathrm{cm}^{2}\right)$ & 393 & 125 & $37.9-364$ & 0.004 \\
\hline Visceral adipose tissue $\left(\mathrm{cm}^{2}\right)$ & 393 & 65.9 & $30.5-134$ & -0.057 \\
\hline Total LBM (kg) & 767 & 63.5 & $50.9-79.4$ & -0.047 \\
\hline Lower extremity LBM (kg) & 767 & 21.8 & $16.7-27.2$ & -0.062 \\
\hline Upper extremity LBM (kg) & 767 & 8.0 & $6.1-10.6$ & -0.044 \\
\hline Central LBM $(\mathrm{kg})$ & 767 & 30.3 & $24.6-37.7$ & -0.030 \\
\hline Total FM $(\mathrm{kg})$ & 767 & 13.8 & $6.3-32.1$ & 0.042 \\
\hline Lower extremity FM (kg) & 767 & 5.2 & $2.3-10.9$ & 0.061 \\
\hline Upper extremity FM (kg) & 767 & 1.59 & $0.74-3.7$ & 0.032 \\
\hline Central FM $(\mathrm{kg})$ & 767 & 6.0 & $2.4-16.1$ & 0.036 \\
\hline Body weight $(\mathrm{kg})$ & 767 & 80.9 & $60.9-110.5$ & -0.013 \\
\hline Body height $(\mathrm{cm})$ & 767 & 181.6 & $167.9-194.8$ & -0.068 \\
\hline Body mass index $\left(\mathrm{kg} / \mathrm{m}^{2}\right)$ & 767 & 24.6 & $19.3-33.3$ & 0.021 \\
\hline \multicolumn{5}{|l|}{ Sex steroid hormones } \\
\hline Total testosterone $(\mathrm{nmol} / \mathrm{l})$ & 767 & 20.4 & $11.0-36.2$ & 0.010 \\
\hline Bioavailable testosterone $(\mathrm{nmol} / \mathrm{l})$ & 767 & 12.0 & $7.0-20.1$ & 0.006 \\
\hline Free testosterone $(\mathrm{nmol} / \mathrm{l})$ & 767 & 0.46 & $0.27-0.75$ & 0.016 \\
\hline Dihydrotestosterone (nmol/l) & 767 & 1.58 & $0.73-3.20$ & 0.014 \\
\hline Androstenedione $(\mathrm{nmol} / \mathrm{l})$ & 767 & 3.8 & $1.8-7.6$ & 0.012 \\
\hline \multicolumn{5}{|l|}{ Covariates: lifestyle and disease } \\
\hline Jogging (km/week) & 767 & $4.3^{\mathrm{b}}$ & $0,0,10^{c}$ & $0.006^{\mathrm{d}}$ \\
\hline Cycling (km/week) & 767 & $23.0^{\mathrm{b}}$ & $0,5,700^{c}$ & $0.006^{\mathrm{d}}$ \\
\hline Additional activities (h/week) & 767 & $2.8^{\mathrm{b}}$ & $0,0,30^{c}$ & $-0.074^{*, d}$ \\
\hline Strength training (yes/no) (\%) & 767 & $19.9^{\mathrm{e}}$ & $17.2-23.0^{f}$ & $-0.076^{\star, d}$ \\
\hline Physically active (yes/no) (\%) & 767 & $75.6^{\mathrm{e}}$ & $72.4-78.6^{f}$ & $-0.068^{d}$ \\
\hline Chronic disease (yes/no) (\%) & 767 & $6.0^{\mathrm{e}}$ & $4.4-7.9^{f}$ & $-0.011^{\mathrm{d}}$ \\
\hline
\end{tabular}

${ }^{*} P<0.05,{ }^{\dagger} P<0.01$.

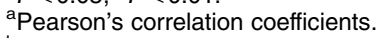

${ }^{\mathrm{b}}$ Arithmetic mean: geometric mean incomputable due to zero-values.

${ }^{\mathrm{c}}$ Minimum, median, and maximum shown due to severely skewed distribution.

'Spearman's rank correlation coefficients.

eProportion of men answering 'yes' (binary variable).

' $95 \%$ Confidence interval for the proportion of men answering 'yes'.

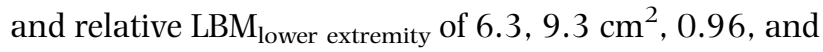
$0.49 \mathrm{~kg}$ respectively. In addition, significant, positive correlations with $\mathrm{CAG}_{n}$ were found for relative $\mathrm{SAT}_{\text {thigh }}$,

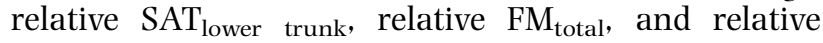
$\mathrm{FM}_{\text {lower extremity }}$ (Fig. 3E-H). A reduction of ten CAG repeats was equivalent with declines in relative

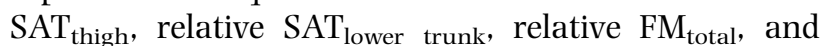

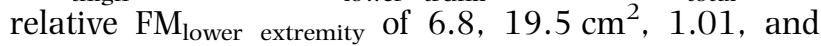
$0.51 \mathrm{~kg}$ respectively. Neither the absolute DEXA outcomes (Table 1) nor the relative outcomes of deep adipose tissues (relative $\mathrm{IMAT}_{\text {thigh }}$ and relative VAT, data not shown) correlated significantly with $\mathrm{CAG}_{n}$.

\section{Analyses with exclusion of men with low TT}

Of the 780 men not taking anabolic steroids, 45 men $(5.8 \%)$ had TT $<12.5 \mathrm{nmol} / \mathrm{l}$. Of these $45 \mathrm{men}$, 33 were genotyped. All significant correlations reported above remained statistically significant when excluding men with low TT. In these subsets of analyses, additional, significant correlations were also found between $\mathrm{CAG}_{n}$ and the following relative outcomes: relative $\mathrm{LBM}_{\text {upper extremity }}(R=-0.083$, $P=0.030)$, relative $\mathrm{FM}_{\text {upper }}$ extremity $(R: 0.084$, $P=0.027)$, and relative $\mathrm{FM}_{\text {central }}(R: 0.085, P=0.039)$.

\section{Multiple regression analyses}

All relative outcomes that correlated significantly with $\mathrm{CAG}_{n}$ in univariate analyses remained significant correlates of $\mathrm{CAG}_{n}$ when controlling for physical activity (jogging, cycling, strength training, and other sports) smoking, chronic disease, medication, and age (Tables 2-6). Consistent with the univariate analyses, a reduction of ten CAG repeats was equivalent with increments in relative muscle thigh $_{\text {, }}$ relative muscle $e_{\text {lower trunk }}$, relative $\mathrm{LBM}_{\text {total }}$, and relative

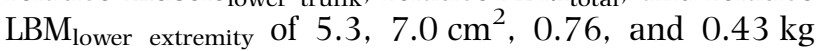
respectively (Tables 2 and 3), and was equivalent with declines in relative $\mathrm{SAT}_{\text {thigh }}$, relative $\mathrm{SAT}_{\text {lower trunk, }}$ 


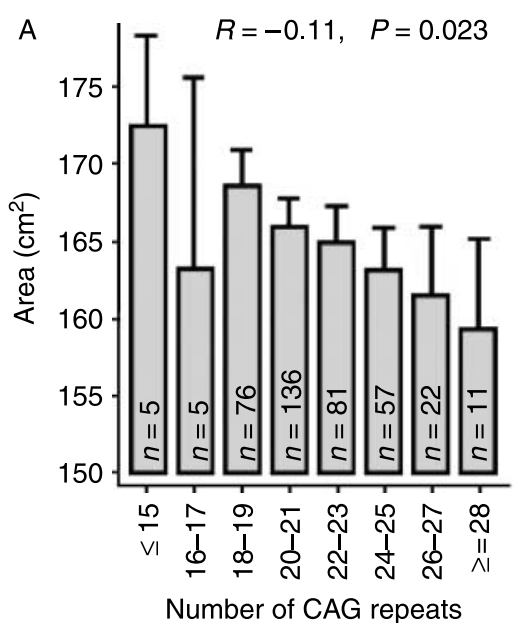

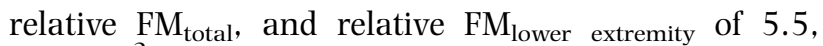
$17.0 \mathrm{~cm}^{2}, 0.79$, and $0.45 \mathrm{~kg}$ respectively (Tables 4 and 5). Again, $\mathrm{CAG}_{n}$ did not correlate with the outcomes of deep adipose tissues, relative $\mathrm{IMAT}_{\text {thigh }}$ and relative VAT (Table 6).

\section{Covariates}

The most consistent positive correlate of all relative outcomes of muscle area and LBM as well as inverse correlate of all relative outcomes of adipose tissue
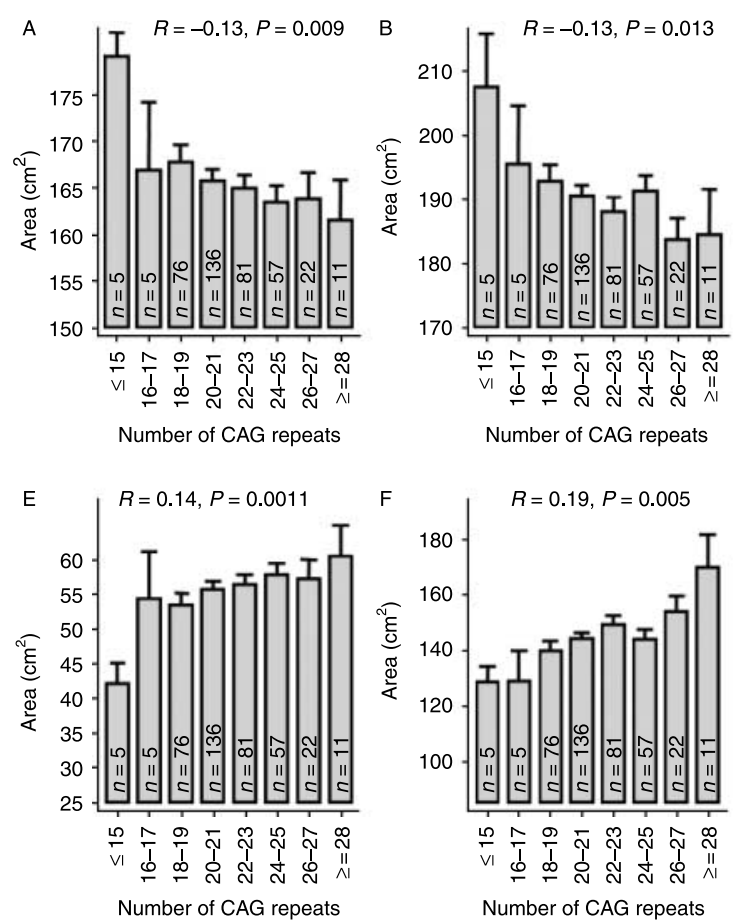

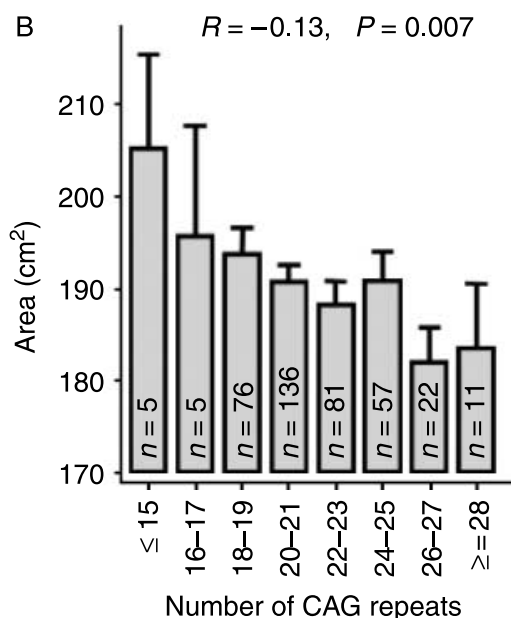

Figure 2 The relationship between the number of CAG repeats and outcomes of body composition in 393 men aged 20-29 years: absolute thigh muscle area $(A)$ and absolute lower trunk muscle area (B). and FM was 'other sports': compared with men not undertaking this activity, $10 \mathrm{~h} /$ week of other sports corresponded to enlargements of $11.1,14.0 \mathrm{~cm}^{2}$, 2.0 , and $0.83 \mathrm{~kg}$ in relative muscle $_{\text {thigh }}$, relative muscle lower trunk, relative $\mathrm{LBM}_{\text {total }}$, and relative $\mathrm{LBM}_{\text {lower extremity }}$ respectively. This was paralleled by reductions in relative $\mathrm{SAT}_{\text {thigh }}$, relative $\mathrm{SAT}_{\text {lower trunk, }}$,

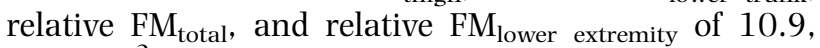
$15.8 \mathrm{~cm}^{2}, 2.2$, and $0.92 \mathrm{~kg}$. The only covariate correlating significantly with relative $\mathrm{IMAT}_{\text {thigh }}$ was jogging, which was also a significant correlate of the
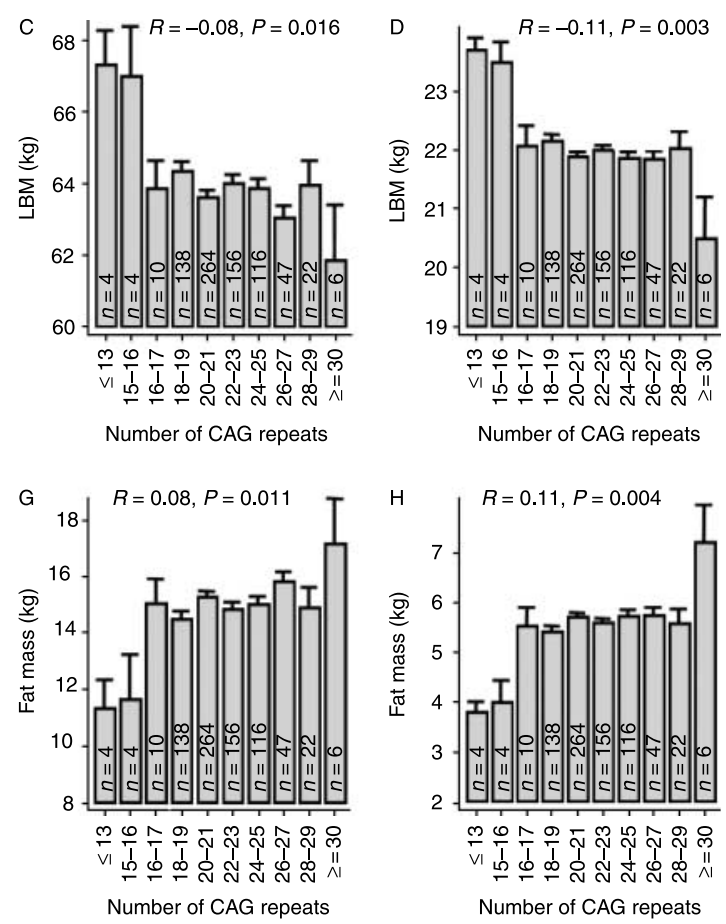

Figure 3 The relationship between the number of CAG repeats and outcomes of body composition in 20-29-year-old men: relative thigh muscle area $(A)$, relative lower trunk muscle area $(B)$, relative total lean body mass $(C)$, relative lower extremity lean body mass $(D)$, relative thigh subcutaneous adipose tissue $(E)$, relative lower trunk subcutaneous adipose tissue $(F)$, relative total fat mass $(G)$, and relative lower extremity fat mass $(\mathrm{H}) . n=393$ in A-B-E-F and $n=767$ in C-D-G-H. 
Table 2 Relative muscle area assessed by magnetic resonance imaging: contribution of the CAG repeat polymorphism, sex steroid hormones, physical activity, smoking, chronic disease, and age to the variation in relative outcomes of thigh and lower trunk muscle areas in 393 young men in the Odense Androgen Study.

\begin{tabular}{|c|c|c|c|c|}
\hline & \multicolumn{2}{|c|}{ Relative thigh muscle area } & \multicolumn{2}{|c|}{ Relative lower trunk muscle area } \\
\hline & Coef. $\left(\mathrm{cm}^{2}\right)$ & $\beta$-coefficient & Coef. $\left(\mathrm{cm}^{2}\right)$ & $\beta$-coefficient \\
\hline CAG repeats (number) & -0.57 & $-0.111^{\star}$ & -0.75 & $-0.102^{*}$ \\
\hline Total testosterone $(\mathrm{nmol} / \mathrm{l})$ & -0.12 & -0.057 & 0.027 & 0.009 \\
\hline Total dihydrotestosterone (nmol/l) & 4.84 & $0.219^{\S}$ & 4.63 & $0.147^{*}$ \\
\hline Total estradiol (pmol/l) & 0.005 & 0.013 & -0.01 & -0.024 \\
\hline Jogging (km/week) & 0.09 & 0.073 & 0.04 & 0.025 \\
\hline Cycling (km/week) & -0.003 & -0.008 & -0.06 & $-0.106^{\star}$ \\
\hline Fitness center (yes/no) & 0.45 & 0.013 & 2.55 & 0.051 \\
\hline Other sports (h/week) & 1.11 & $0.342^{\|}$ & 1.41 & $0.306^{\| \prime}$ \\
\hline Smoking (cigarettes/day) & -0.24 & $-0.131^{\dagger}$ & -0.12 & -0.044 \\
\hline Chronic disease (no medication) & -14.12 & $-0.100^{\ddagger}$ & -14.89 & $-0.074^{*}$ \\
\hline Chronic disease (medically treated) & -2.20 & -0.028 & 0.61 & 0.005 \\
\hline Age (years) & 0.40 & 0.095 & -0.23 & -0.033 \\
\hline & & $R^{2}: 0.232$ & & $R^{2}: 0.154$ \\
\hline
\end{tabular}

Conventional coefficients and normalized $\beta$-coefficients. ${ }^{*} P<0.05,{ }^{\dagger} P<0.01,{ }^{\ddagger} P<0.001,{ }^{\S} P<0.0001,{ }^{~} P<10^{-6}$ (all apply for both coefficients).

other outcome of deep adipose tissue, VAT. Jogging also correlated positively with relative $\mathrm{LBM}_{\text {total }}$ and relative $\mathrm{LBM}_{\text {lower extremity }}$ and inversely with relative $\mathrm{FM}_{\text {total }}$ and relative $\mathrm{FM}_{\text {lower extremity. }}$ Chronic disease without concomitant medication had a negative impact on relative muscle $_{\text {thigh }}$, relative muscle lower trunk, and relative $\mathrm{LBM}_{\text {lower extremity }}$ Smoking was significantly correlated with decreased relative muscle thigh, $_{\text {, and }}$ noticeably, relative VAT was $12.0 \mathrm{~cm}^{2}$ higher in 29-year-old men than in 20-year-old men. The effect of $\mathrm{CAG}_{n}$ on any outcome did not change significantly when the analyses were performed separately in physically active men and in physically inactive men.

\section{$\mathrm{CAG}_{\mathrm{n}}$ and circulating androgens}

No significant relationships were found between $\mathrm{CAG}_{n}$ and TT, bioavailable testosterone, DHT, androstenedione, or sex hormone binding globulin (SHBG; $P=0.78$, $P=0.86, P=0.69, P=0.69$, and $P=0.80) . C^{2} G_{n}$ did correlate positively with $\mathrm{E}_{2}(R=0.097, P=0.007)$. In an additional multivariate model incorporating $\mathrm{CAG}_{n}$, SHBG, and TT as independent variables and $\mathrm{E}_{2}$ as the dependent variable, $\mathrm{E}_{2}$ correlated positively with $\mathrm{CAG}_{n}$ $(R=0.094, P=0.003)$ and TT $\left(R=0.518, P<10^{-25}\right)$, but inversely with SHBG $\left(R=-0.213, P<10^{-5}\right)$.

\section{Discussion}

This is the first large population-based study of the effects of the CAG repeat polymorphism of the androgen receptor gene on muscle area, LBM, and adipose tissue in young men. The effect of this common allelic polymorphism on muscle size could be demonstrated in a male population aged 20-29 years, and could not be attributed to any of the covariates examined,

Table 3 Relative lean body mass assessed by dual-energy X-ray absorptiometry: contribution of the CAG repeat polymorphism, sex steroid hormones, physical activity, smoking, chronic disease, and age to the variation in relative outcomes of total and lower extremity lean body mass in 767 young men in the Odense Androgen Study.

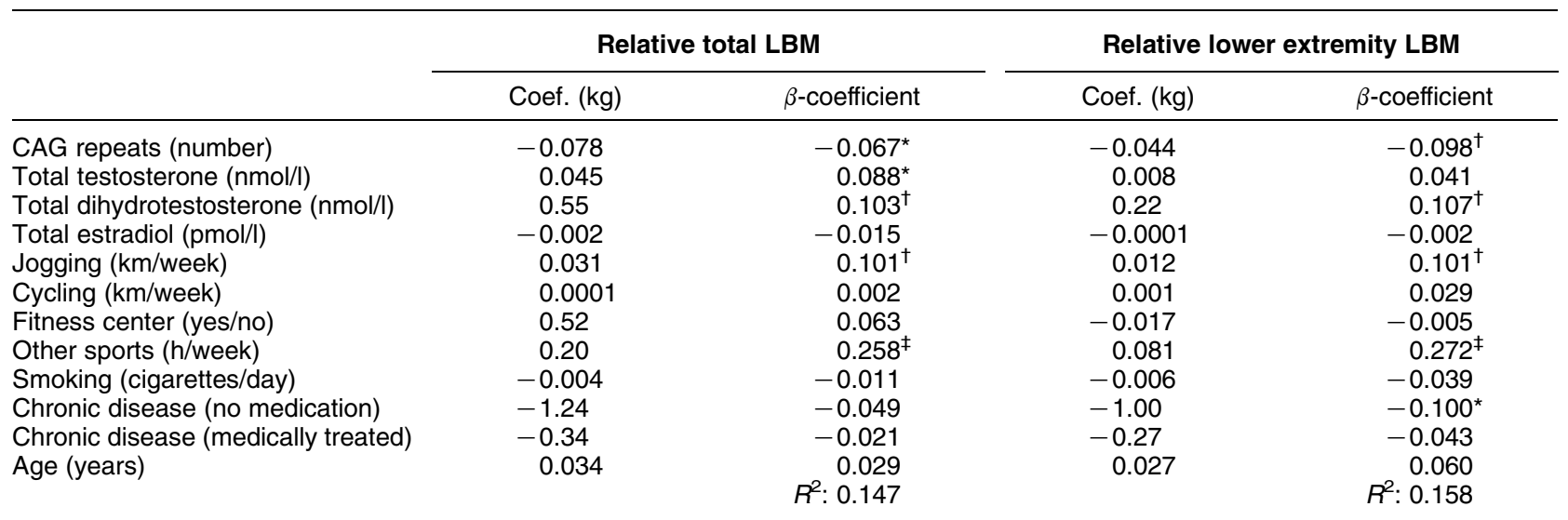

Conventional coefficients and normalized $\beta$-coefficients. ${ }^{\star} P<0.05,{ }^{\dagger} P<0.01,{ }^{\ddagger} P<10^{-12}$ (all apply for both coefficients). 
Table 4 Relative subcutaneous adipose tissue assessed by magnetic resonance imaging: contribution of the CAG repeat polymorphism, physical activity, smoking, chronic disease, and age to the variation in relative outcomes of subcutaneous adipose tissues (SAT) in 393 young men in the Odense Androgen Study.

\begin{tabular}{|c|c|c|c|c|}
\hline & \multicolumn{2}{|c|}{ Relative thigh SAT } & \multicolumn{2}{|c|}{ Relative lower trunk SAT } \\
\hline & Coef. $\left(\mathrm{cm}^{2}\right)$ & $\beta$-coefficient & Coef. $\left(\mathrm{cm}^{2}\right)$ & $\beta$-coefficient \\
\hline CAG repeats (number) & 0.55 & $0.111^{*}$ & 1.70 & $0.164^{\dagger}$ \\
\hline Jogging (km/week) & -0.05 & -0.041 & -0.003 & -0.001 \\
\hline Cycling (km/week) & 0.01 & 0.030 & 0.09 & $0.104^{*}$ \\
\hline Fitness center (yes/no) & -0.77 & -0.026 & -4.55 & -0.065 \\
\hline Other sports (h/week) & -1.09 & $-0.348^{\ddagger}$ & -1.58 & $-0.244^{\ddagger}$ \\
\hline Smoking (cigarettes/day) & 0.21 & $0.115^{\star}$ & 0.09 & 0.023 \\
\hline $\begin{array}{l}\text { Chronic disease } \\
\text { (no medication) }\end{array}$ & 14.73 & $0.108^{\dagger}$ & 11.34 & $0.040^{*}$ \\
\hline $\begin{array}{l}\text { Chronic disease } \\
\text { (medically treated) }\end{array}$ & 2.42 & 0.032 & -7.96 & -0.050 \\
\hline Age (years) & -0.46 & $R^{2}: 0.096^{*}$ & -1.10 & $R^{2}: 0.110^{*}$ \\
\hline
\end{tabular}

Conventional coefficients and normalized $\beta$-coefficients. ${ }^{\star} P<0.05,{ }^{\dagger} P<0.01,{ }^{\ddagger} P<0.0001$ (all apply for both coefficients).

including sex steroid concentrations. Two main outcomes (thigh muscle area and lower trunk muscle area) correlated significantly and inversely with $\mathrm{CAG}_{n}$. Additionally, inverse correlations were also found for the relative outcomes of thigh muscle area, lower trunk muscle area, lower extremity LBM, and total LBM. In men with normal TT levels, upper extremity LBM also correlated inversely with $\mathrm{CAG}_{n}$.

Our study takes advantage of not being susceptible to neuroregulatory defects in the feed-forward and feed-back systems of the HPG axis, which has been reported in healthy aging men (16-18). Moreover, age per se as well as the increased prevalence of chronic diseases, use of medication, and obesity with age will affect circulating androgens negatively (19-23). This may mask an effect of the CAG repeat polymorphism at older ages, because the effects are best observed in eugonadal men (24) and because adjustment for measures such as disease and medication are analytically challenging.
The participants were randomly drawn from the Danish Central Personal Registry $(25,26)$, and they matched the background population of 20-29-year-old men as regards sociodemography, body mass index, physical activity, smoking, alcohol intake, medication, and prevalence of chronic diseases (7). The subjects were carefully interviewed and examined to adjust for any confounding impact of lifestyle or disease. The narrow age interval limits the potential bias of cohort effects. The young age limits the exposure to potential environmental confounders, and provides the optimal setting for examinations of physiological relationships in a period in life when peak muscle mass is attained $(27,28)$. Thus, the results indicate that the CAG repeat polymorphism may be related to variations in accretion of muscular tissue, while studies of older men may also reflect variations in the age-related loss of muscle.

Only one previous study (5) examined the relationship between $\mathrm{CAG}_{n}$ and fat-free mass; our results are in disagreement with the results of Walsh et al. (5),

Table 5 Relative fat mass assessed by dual-energy X-ray absorptiometry: contribution by the CAG repeat polymorphism, physical activity, smoking, chronic disease, and age to the variation in relative outcomes of total and lower extremity fat mass in 767 young men in the Odense Androgen Study.

\begin{tabular}{|c|c|c|c|c|}
\hline & \multicolumn{2}{|c|}{ Relative total fat mass } & \multicolumn{2}{|c|}{ Relative lower extremity fat mass } \\
\hline & Coef. (kg) & $\beta$-coefficient & Coef. (kg) & $\beta$-coefficient \\
\hline CAG repeats (number) & 0.079 & $0.064^{\star}$ & 0.045 & $0.093^{\dagger}$ \\
\hline Jogging (km/week) & -0.031 & $-0.096^{\dagger}$ & -0.012 & $-0.097^{\dagger}$ \\
\hline Cycling (km/week) & 0.000 & 0.002 & -0.001 & 0.020 \\
\hline Fitness center (yes/no) & -0.51 & -0.058 & 0.031 & -0.009 \\
\hline Other sports (h/week) & -0.22 & $-0.275^{\ddagger}$ & -0.092 & $-0.289^{\ddagger}$ \\
\hline Smoking (cigarettes/day) & 0.002 & 0.004 & 0.005 & 0.031 \\
\hline $\begin{array}{l}\text { Chronic disease } \\
\text { (no medication) }\end{array}$ & 1.44 & 0.053 & 1.09 & $0.103^{*}$ \\
\hline $\begin{array}{l}\text { Chronic disease } \\
\text { (medically treated) }\end{array}$ & 0.35 & 0.039 & 0.35 & 0.052 \\
\hline Age (years) & -0.029 & $R^{-0.027}: 0.12$ & -0.029 & $\begin{aligned} &-0.061 \\
& R^{2}: 0.14\end{aligned}$ \\
\hline
\end{tabular}

Conventional coefficients and normalized $\beta$-coefficients. ${ }^{\star} P<0.05,{ }^{\dagger} P<0.01,{ }^{\ddagger} P<10^{-12}$ (all apply for both coefficients). 
Table 6 Relative deep adipose tissue assessed by magnetic resonance imaging: contribution of the CAG repeat polymorphism, physical activity, smoking, chronic disease, and age to the variation in relative outcomes of deep adipose tissues in 393 young men in the Odense Androgen Study.

\begin{tabular}{|c|c|c|c|c|}
\hline & \multicolumn{2}{|c|}{ Relative thigh i.m. adipose tissue } & \multicolumn{2}{|c|}{ Relative visceral adipose tissue } \\
\hline & Coef. $\left(\mathrm{cm}^{2}\right)$ & $\beta$-coefficient & Coef. $\left(\mathrm{cm}^{2}\right)$ & $\beta$-coefficient \\
\hline CAG repeats (number) & 0.005 & 0.006 & -0.19 & -0.028 \\
\hline Jogging (km/week) & -0.021 & $-0.108^{\dagger}$ & -0.17 & $-0.114^{\star}$ \\
\hline Cycling (km/week) & -0.005 & -0.072 & -0.02 & -0.042 \\
\hline Fitness center (yes/no) & 0.082 & 0.014 & -2.00 & -0.044 \\
\hline Other sports (h/week) & -0.049 & -0.092 & -0.12 & -0.030 \\
\hline Smoking (cigarettes/day) & 0.005 & 0.018 & -0.13 & -0.056 \\
\hline $\begin{array}{l}\text { Chronic disease } \\
\text { (no medication) }\end{array}$ & 0.94 & 0.040 & 11.81 & 0.065 \\
\hline $\begin{array}{l}\text { Chronic disease } \\
\text { (medically treated) }\end{array}$ & 0.96 & 0.073 & 4.01 & 0.039 \\
\hline Age (years) & 0.069 & $R^{2}: \begin{array}{l}0.084 \\
0.05\end{array}$ & 1.20 & $R^{2}: 0.186^{\ddagger}$ \\
\hline
\end{tabular}

Conventional coefficients and normalized $\beta$-coefficients. ${ }^{\star} P<0.05,{ }^{\dagger} P<0.01,{ }^{\ddagger} P<0.001$ (all apply for both coefficients).

who found that absolute and relative fat-free mass correlated positively with $\mathrm{CAG}_{n}$ in two cohorts of 294 men (55-93 years) and 112 men (19-90 years) respectively. The age difference between our cohort and the cohorts studied by Walsh et al. is obvious. Their findings were discussed in context with aging: in our young cohort, we found no relationship between $\mathrm{CAG}_{n}$ and circulating androgens, which were assayed after extraction and chromatography to give high precision and accuracy. Neither did Van Pottelbergh et al. (29) in a study of 273 community-dwelling healthy men, aged between 71 and 86 years, find a relationship between $\mathrm{CAG}_{n}$ and circulating androgens. However, in the study by Walsh et al., total and bioavailable testosterone were lower in men with fewer repeats at older ages, suggesting a gene-by-age interaction. Also, Krithivas et al. reported that longitudinal, intra-individual declines in total and bioavailable testosterone with age were significantly, inversely correlated with $\mathrm{CAG}_{n}$ in the Massachusetts Male Aging Study (6). Reduced central androgen receptor activity in men with longer alleles was hypothesized to diminish the negative feedback on the HPG axis, leading to higher androgen levels $(5,6)$. Thus, the direct, positive effects of having few CAG repeats on muscle size in young men (toward which our data point) may be overruled by a concomitant decline in androgen levels in elderly men with few repeats. The positive relationship between $\mathrm{CAG}_{n}$ and $\mathrm{E}_{2}$ in our cohort is interesting, but it needs to be replicated in other cohorts. In addition, the relationship between $\mathrm{CAG}_{n}$ and $\mathrm{E}_{2}$-dependent parameters should be examined. Zitzmann et al. have proposed that relationships between $\mathrm{CAG}_{n}$ and any outcome are most likely to be identified in men with normal levels of circulating androgens (24). Our additional observation of a negative correlation between $\mathrm{CAG}_{n}$ and the relative outcome of upper extremity LBM in men with normal TT levels supports this view.
Using two modalities, we also investigated eight outcomes of adiposity $\left(\mathrm{SAT}_{\text {thigh }}\right.$, $\mathrm{IMAT}_{\text {thigh }}, \mathrm{SAT}_{\text {lower trunk }}$, and VAT assessed by MRI and $\mathrm{FM}_{\text {total }}, \mathrm{FM}_{\text {lower extremity, }}$ $\mathrm{FM}_{\text {upper extremity, and }} \mathrm{FM}_{\text {central }}$ assessed by DEXA) in relation to $\mathrm{CAG}_{n}$ : positive correlations were seen between $\mathrm{CAG}_{n}$ and $\mathrm{SAT}_{\text {thigh }}$, $\mathrm{SAT}_{\text {lower trunk }}, \mathrm{FM}_{\text {total }}$, and $\mathrm{FM}_{\text {lower }}$ extremity upon adjustment of these parameters for total thigh area, total lower trunk area, body weight, and total lower extremity mass respectively. The relationships remained statistically significant after correction for covariates. It may be a direct effect of increased AR activity in men with shorter alleles, because the AR has been shown to mediate the inhibitory effects of TT and DHT on mesenchymal stem cell differentiation toward adipocytes (30). Our results are in agreement with Zitzmann et al. (2003), who found the same relationship with FM in a crosssectional study involving 106 healthy 20-50-year-old men. The median age of their cohort (28 years) was very close to that of our cohort (25.7 years).

The differences in size and mobilization processes between subcutaneous and visceral adipocytes have previously been put in context with variations in circulating androgens (31). The significant impact of $\mathrm{CAG}_{n}$ on $\left(\mathrm{SAT}_{\text {thigh }}\right.$ and $\left.\mathrm{SAT}_{\text {lower trunk }}\right)$ and lacking impact on deeper adipose tissues (IMAT thigh $_{\text {and VAT) }}$ are interesting findings: they may indicate that actions of androgens on male adipose tissues are mainly associated with favorable impacts on subcutaneous compartments. This is in accordance with interventional studies of testosterone replacement therapy, in which subcutaneous compartments diminished $(32,33)$, while only one small, older study reported diminished amounts of VAT (34). The interpretation of cross-sectional data is uncertain, but our study strongly indicates that VAT increases considerably from age 20 to 29 years, and that, on average, VAT is further increased in middle-aged men (21). Therefore, the lack of impact of $\mathrm{CAG}_{n}$ on VAT in our study could also reflect 
that these young men have yet to encounter the point in life where they can no longer convert a positive energy balance into deposition of fat in subcutaneous stores. Our data do not rule out the possibility that the CAG repeat polymorphism may also modify VAT, once the deposition into deeper adipose tissues accelerates later in life.

The statistically significant results obtained in this study are - in our opinion - also physiologically relevant with $\sim 4-5 \%$ increments in thigh and lower trunk muscle areas and 13-16\% reductions in SAT areas per ten CAG repeat decreases. Nevertheless, this apparent genetic effect was not as strong as the effect of a lifestyle with many weekly hours spent in sports. We have investigated 14 absolute and 14 relative outcomes of body composition. All relationships with $\mathrm{CAG}_{n}-$ with respect to the trend - are in congruence: inverse relationships with all outcomes of muscle areas and LBM and - vice versa - positive relationships with all outcomes of SAT areas and FM. Our data indicate that having short $\mathrm{CAG}$ repeats may be a genetic advantage in terms of muscle accretion. However, we are not aware of any data demonstrating an effect of this polymorphism on muscle function.

In conclusion, we have demonstrated a significant effect of the CAG repeat polymorphism of the androgen receptor gene on thigh and lower trunk muscle areas in young men. This study is the first to demonstrate an inverse relationship between the number of CAG repeats and muscle area. The results need to be confirmed in other young, male cohorts.

\section{Declaration of interest}

The authors declare that there is no conflict of interest that could be perceived as prejudicing the impartiality of the research reported.

\section{Funding}

This work was supported by the World-Anti Doping Agency; the Danish Ministry of Culture; Novo Nordisk Scandinavia AB; Pfizer Denmark; Institute of Clinical Research, University of Southern Denmark; Odense University Hospital.

\section{References}

1 Snyder PJ. Hypogonadism in elderly men - what to do until the evidence comes. New England Journal of Medicine 2004350 440-442.

2 Mhatre AN, Trifiro MA, Kaufman M, Kazemi-Esfarjani P, Figlewicz D, Rouleau G \& Pinsky L. Reduced transcriptional regulatory competence of the androgen receptor in X-linked spinal and bulbar muscular atrophy. Nature Genetics 19935 184-188.

3 Tut TG, Ghadessy FJ, Trifiro MA, Pinsky L \& Yong EL. Long polyglutamine tracts in the androgen receptor are associated with reduced trans-activation, impaired sperm production, and male infertility. Journal of Clinical Endocrinology and Metabolism 199782 3777-3782.
4 Zitzmann M, Gromoll J, von Eckardstein A \& Nieschlag E. The CAG repeat polymorphism in the androgen receptor gene modulates body fat mass and serum concentrations of leptin and insulin in men. Diabetologia 200346 31-39.

5 Walsh S, Zmuda JM, Cauley JA, Shea PR, Metter EJ, Hurley BF, Ferrell RE \& Roth SM. Androgen receptor CAG repeat polymorphism is associated with fat-free mass in men. Journal of Applied Physiology 200598 132-137.

6 Krithivas K, Yurgalevitch SM, Mohr BA, Wilcox CJ, Batter SJ, Brown M, Longcope C, McKinlay JB \& Kantoff PW. Evidence that the CAG repeat in the androgen receptor gene is associated with the age-related decline in serum androgen levels in men. Journal of Endocrinology 1999162 137-142.

7 Nielsen TL, Wraae K, Brixen K, Hermann AP, Andersen M \& Hagen C. Prevalence of overweight, obesity and physical inactivity in 20- to 29-year-old, Danish men. Relation to sociodemography, physical dysfunction and low socioeconomic status: the Odense Androgen Study. International Journal of Obesity 200630 805-815.

8 Nielsen TL, Hagen C, Wraae K, Brixen K, Petersen PH, Haug E, Larsen R \& Andersen M. Visceral and subcutaneous adipose tissue assessed by magnetic resonance imaging in relation to circulating androgens, sex hormone-binding globulin, and luteinizing hormone in young men. Journal of Clinical Endocrinology and Metabolism 200792 2696-2705.

9 Parker CR Jr, Ellegood JO \& Mahesh VB. Methods for multiple steroid radioimmunoassay. Journal of Steroid Biochemistry $197561-8$.

10 Lykkesfeldt G, Bennett P, Lykkesfeldt AE, Micic S, Moller S \& Svenstrup B. Abnormal androgen and oestrogen metabolism in men with steroid sulphatase deficiency and recessive X-linked ichthyosis. Clinical Endocrinology 198523 385-393.

11 Vermeulen A, Verdonck L \& Kaufman JM. A critical evaluation of simple methods for the estimation of free testosterone in serum. Journal of Clinical Endocrinology and Metabolism $1999 \mathbf{8 4}$ 3666-3672.

12 Engholm R, Dubinskiy A, Larsen R, Hanson LG \& Christoffersen BO. An adipose segmentation and quantification scheme for the intra abdominal region on minipigs - art. no. 61443U.; U1443. Proceedings of Society of Photo-Optical Instrumentation Engineers (SPIE) $2006 \mathbf{6 1 4 4}$ U1443.

13 Allison DB, Paultre F, Goran MI, Poehlman ET \& Heymsfield SB. Statistical considerations regarding the use of ratios to adjust data. International Journal of Obesity and Related Metabolic Disorders 1995 $19644-652$.

14 Goran MI, Allison DB \& Poehlman ET. Issues relating to normalization of body fat content in men and women. International Journal of Obesity and Related Metabolic Disorders $199519638-643$.

15 Altman DG. Practical Statistics for Medical Research. Ed. DG Altman. London: Chapman \& Hall/CRC 1991.

16 Veldhuis JD, Zwart A, Mulligan T \& Iranmanesh A. Muting of androgen negative feedback unveils impoverished gonadotropinreleasing hormone/luteinizing hormone secretory reactivity in healthy older men. Journal of Clinical Endocrinology and Metabolism 200186 529-535.

17 Liu PY, Takahashi PY, Roebuck PD, Iranmanesh A \& Veldhuis JD. Aging in healthy men impairs recombinant human luteinizing hormone (LH)-stimulated testosterone secretion monitored under a two-day intravenous pulsatile LH clamp. Journal of Clinical Endocrinology and Metabolism 200590 5544-5550.

18 Mulligan T, Iranmanesh A, Kerzner R, Demers LW \& Veldhuis JD. Two-week pulsatile gonadotropin releasing hormone infusion unmasks dual (hypothalamic and Leydig cell) defects in the healthy aging male gonadotropic axis. European Journal of Endocrinology 1999141 257-266.

19 Handelsman DJ. Testicular dysfunction in systemic disease. Endocrinology and Metabolism Clinics of North America 199423 839-856.

20 Vanderpump MP \& Tunbridge WM. The effects of drugs on endocrine function. Clinical Endocrinology 199339 389-397. 
21 Couillard C, Gagnon J, Bergeron J, Leon AS, Rao DC, Skinner JS, Wilmore JH, Despres JP \& Bouchard C. Contribution of body fatness and adipose tissue distribution to the age variation in plasma steroid hormone concentrations in men: the HERITAGE Family Study. Journal of Clinical Endocrinology and Metabolism $2000851026-1031$.

22 Giagulli VA, Kaufman JM \& Vermeulen A. Pathogenesis of the decreased androgen levels in obese men. Journal of Clinical Endocrinology and Metabolism 1994 79 997-1000.

23 Seidell JC, Bjorntorp P, Sjostrom L, Kvist H \& Sannerstedt R. Visceral fat accumulation in men is positively associated with insulin, glucose, and C-peptide levels, but negatively with testosterone levels. Metabolism 199039 897-901.

24 Zitzmann M \& Nieschlag E. The CAG repeat polymorphism within the androgen receptor gene and maleness. International Journal of Andrology 200326 76-83.

25 Frank L. Epidemiology. When an entire country is a cohort. Science $20002872398-2399$.

26 Frank L. Epidemiology. The epidemiologist's dream: Denmark. Science 2003301163.

27 Borges O. Isometric and isokinetic knee extension and flexion torque in men and women aged 20-70. Scandinavian Journal of Rehabilitation Medicine 198921 45-53.

28 Larsson L, Grimby G \& Karlsson J. Muscle strength and speed of movement in relation to age and muscle morphology. Journal of Applied Physiology 197946 451-456.

29 Van Pottelbergh I, Lumbroso S, Goemaere S, Sultan C \& Kaufman JM. Lack of influence of the androgen receptor gene CAG repeat polymorphism on sex steroid status and bone metabolism in elderly men. Clinical Endocrinology 200155 659-666.
30 Singh R, Artaza JN, Taylor WE, Gonzalez-Cadavid NF \& Bhasin S Androgens stimulate myogenic differentiation and inhibit adipogenesis in $\mathrm{C} 3 \mathrm{H}$ 10T1/2 pluripotent cells through an androgen receptor-mediated pathway. Endocrinology $2003 \mathbf{1 4 4}$ 5081-5088.

31 Bjorntorp P. Adipose tissue distribution and function. International Journal of Obesity 199115 67-81.

32 Bhasin S, Parker RA, Sattler F, Haubrich R, Alston B, Umbleja T \& Shikuma CM. Effects of testosterone supplementation on whole body and regional fat mass and distribution in human immunodeficiency virus-infected men with abdominal obesity. Journal of Clinical Endocrinology and Metabolism $2007 \mathbf{9 2}$ 1049-1057.

33 Munzer T, Harman SM, Hees P, Shapiro E, Christmas C, Bellantoni MF, Stevens TE, O'Connor KG, Pabst KM, St Clair C, Sorkin JD \& Blackman MR. Effects of GH and/or sex steroid administration on abdominal subcutaneous and visceral fat in healthy aged women and men. Journal of Clinical Endocrinology and Metabolism 200186 3604-3610.

34 Marin P, Holmang S, Jonsson L, Sjostrom L, Kvist H, Holm G, Lindstedt G \& Bjorntorp P. The effects of testosterone treatment on body composition and metabolism in middle-aged obese men. International Journal of Obesity and Related Metabolic Disorders 1992 16 991-997.

Received 31 January 2010

Accepted 3 February 2010 